\title{
3 Language ideologies, practices and policies in Kanaky/New Caledonia
}

\section{Julia Sallabank}

\subsection{Introduction}

From colonisation by France in 1853 until the Accords of 1989 and 1998, the indigenous Kanak people of New Caledonia, and their culture and languages, were marginalised and children were forbidden from speaking their home languages at school. Education still follows the French curriculum, although gradual devolution of powers is under way. Little sociolinguistic research has been carried out in Kanaky/New Caledonia, especially into the processes of language shift and change, language attitudes and ideologies in relation to language policy; the only readily available study is Schooling (1990), which focuses on the role of social networks in language maintenance. The small-scale study described in this chapter investigates attitudes towards language and language practices in Pweevo, Northern Province, and then goes on to examine the responses of both individuals and government agencies.

\subsubsection{Socio-economic and political background}

Kanaky/New Caledonia is an archipelago in the Pacific Ocean, approximately 1500 kilometres (950 miles) east of Australia and about 540 kilometres (335 miles) south-west of Vanuatu. The main island, known as Grande Terre, is approximately $50 \mathrm{~km}$ (30 miles) wide, but $500 \mathrm{~km}$ (310 miles) long (see Figure 3.1). The culture, socio-economic background, colonial history and decolonisation process are all intricately linked with language policies, practices, attitudes and ideologies.

I owe a great debt to Aurélie Cauchard, who was extremely generous with her time, expertise and contacts. Her discussions of findings and constructive comments on this paper have contributed greatly to its analysis and accuracy. Any errors or misconceptions are entirely mine. Claire Moyse-Faurie, Research Director, LACITO-CNRS, Paris and University of New Caledonia, welcomed me to Nouméa and the University of New Caledonia and arranged permission to reproduce the map in Figure 3.1. In Pweevo, Jean-Marc and Ghislaine Pidjo, Didace and Dany Nonghai, Carine Nonghai, Ignacia Wala and numerous other residents participated and helped. I am also grateful to Stéphanie Geneix of l'Académie des Langues Kanak for inviting me to attend the meeting 'Espaces Oralité' 22-23 March 2013. 


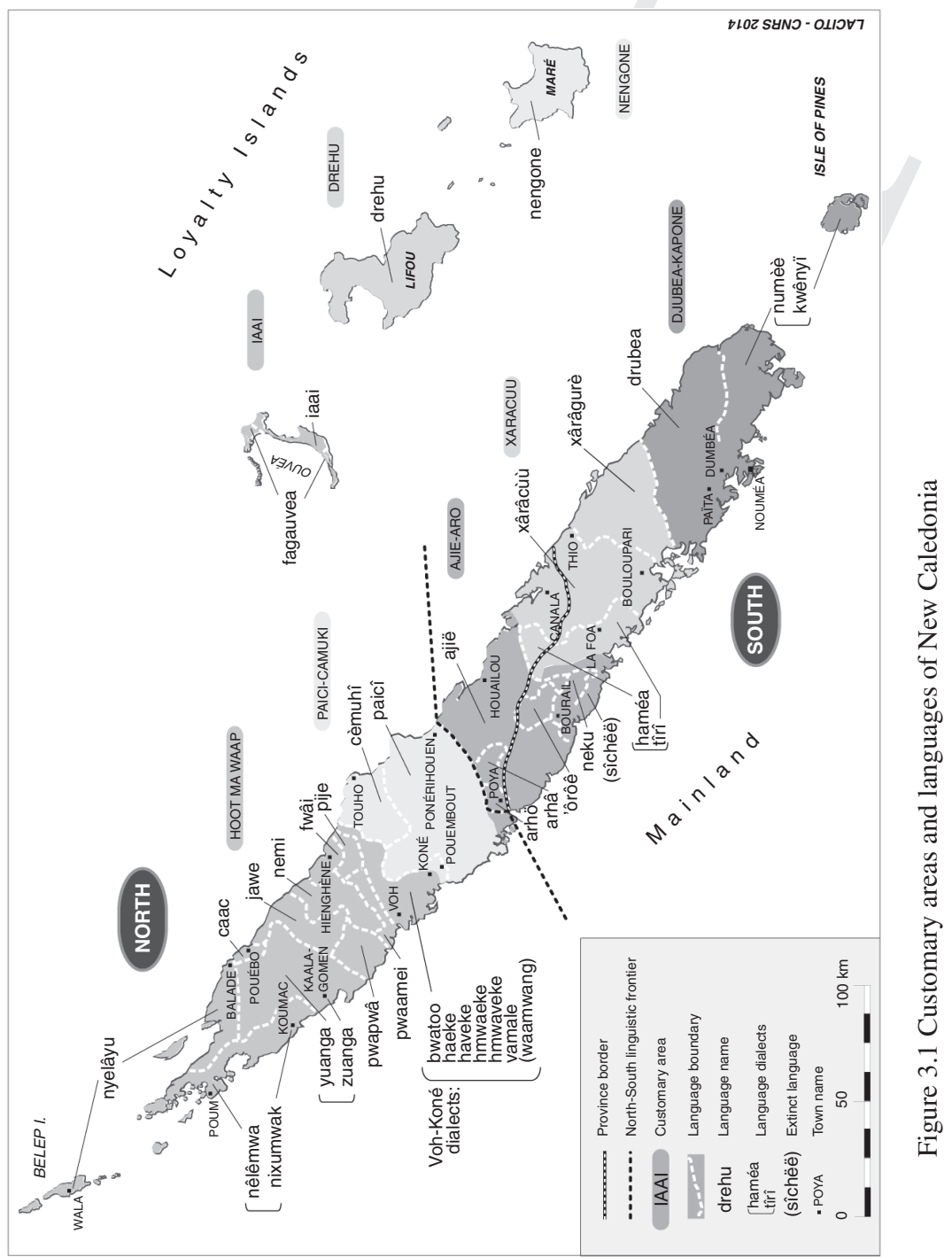


The population of New Caledonia was estimated by the government to be 264,022 in July 2013. According to the 2009 census, approximately 40.3 per cent of the population are of indigenous Kanak (Melanesian) origin. People of European origin constitute 29.2 per cent of the populace, with the rest originating mainly from other parts of Oceania or East Asia. The population is diversifying, as half of those who were not born in New Caledonia had arrived since 1997; most of the non-indigenous population has settled in the capital, Nouméa.

'New Caledonia' was given its European name by Captain James Cook, who landed in Northern Province in 1774 and thought that the landscape, with its hills, forests and waterfalls, resembled that of Scotland. The name preferred by indigenous and pro-independence groups is 'Kanaky'. Chappell (2013) remarks that its supporters regard the term 'Kanak' as inclusive, while opponents see it as exclusive and prefer 'Caledonian'. In this chapter I will try to use both. ${ }^{1}$ The term Kanak is derived from the Hawaiian word kanaka, 'man' or 'human being', which, according to Chappell (2013), was introduced via shipboard and plantation pidgins in the nineteenth century. Chappell remarks that both 'Kanak' and 'Caledonian' are modern identity formations that resulted from colonial confrontations. Unlike French adjectives and nouns, the word kanak does not inflect for gender or number, reflecting the morphology of Kanak languages.

Kanaky/New Caledonia contains 25 per cent of the world's known nickel deposits, which attracts migrant workers and was one reason for colonial exploitation. Nickel is still the mainstay of the economy despite price fluctuations. Tourism is growing and there is some fishing, although local people are only allowed to sell their fish through government-sponsored co-operatives. Large-scale economic activity is largely confined to Southern Province, where settlers and recent immigrants make up nearly three-quarters of the population. In contrast, Kanaks make up the overwhelming majority of the population of Northern Province (85 per cent) (McLellan 2005).

By far the largest proportion of economic exchange is with France (IEOM 2011). Imported French goods, including food, predominate in shops. Subsidies from France contribute between 15 per cent and 20 per cent to the gross domestic product, and it could be argued that economic dependency is in the interests of the political status quo; however, given the economic situation in Europe, such subsidies hardly seem sustainable.

After annexation by France in 1853, Kanaks were expropriated from their lands, which were sold cheaply to colonists. According to my informants, in traditional Kanak society, land belongs to the clan; there was no 'spare land' which might be occupied by colonists. Displaced people were sent to other groups' lands (which caused conflict between indigenous groups) and were confined to reservations which were too small to support them using traditional 
agricultural practices (Winslow 1991). In 1878 and 1917, dissatisfaction erupted into revolts, which were put down brutally.

The Kanak population halved between 1878 and 1921 due to slavery and disease brought by settlers. As the population recovered during the twentieth century, Kanaks began to demand the return of expropriated land (Winslow 1991). Following the Second World War, colonial policy became more liberal, and in 1956 New Caledonia became a 'territorial collectivity' of France. Kanaks became increasingly frustrated at the ineffectiveness of land reform and started to demand independence. In the 1970s and 1980s, unrest culminated in what are euphemistically known as Les Événements ('The Events') of 1984, during which much of the North was effectively out of government control. Ironically, this period is remembered fondly by middle-aged people in Pweevo, Northern Province, where my research was conducted. As government schools were not functioning, separatists set up their own schools called l'École Populaire Kanak (hereafter EPK, Kanak Popular Schools), which taught a 'Kanak curriculum' including indigenous languages and culture and local flora and fauna (Gauthier 1996; Small 1996). Meanwhile, Catholic schools continued to run as normal; one interviewee recalled how she had watched her friends at the EPK enviously over the fence. After intense negotiation, the Matignon Agreement was signed in 1988, followed by the Nouméa Accord in 1998. The latter provides for a staged transfer of powers and is seen by Kanaks as a roadmap to self-determination (Manassah 2013), although pro-French politicians argue that it does not necessarily lead to full autonomy. One of its provisions was for a Kanak Languages Academy, which was eventually founded in 2007 (see Section 3.3). Responsibility for primary education was devolved in 2000, and higher education is due to be devolved in 2015.

Kanak children were only given widespread access to public schools from $1953 .^{2}$ There is significant educational under-achievement among Kanak youth (Salaün 2005; Nicolas 2010; Leclerc 2014). French is the language of education, literacy and public life; English and Spanish are taught as the main foreign languages, despite the fact that the nearest places where Spanish might be used are the Philippines and Easter Island, both thousands of kilometres away. Given that half the population is aged under thirty, ${ }^{3}$ combined with under-employment in the north and high levels of alcoholism and drug use (leading to a high accident rate), there is potential for a demographic time-bomb. Since 1998, the government has made efforts to heal the deep rifts in New Caledonian society. Official rhetoric in the twenty-first century promotes a 'common destiny' and, since 2010, the flag of the Kanak independence movement has been permitted to be flown in public places (alongside the French tricolour), although it is rejected by anti-independence parties. A referendum on independence is due to be held 
by 2018 , but at the time of writing, there is a political stalemate following the resignation in December 2014 of the government elected in May of that year, which was supposed to manage the lead-up to the referendum. ${ }^{4}$ There are fears that the process will be divisive and could lead once again to violent confrontations (Fisher 2013).

Mistrust of the colonial powers and resentment at their treatment persists among Kanak people. Some of my interviewees expressed the opinion that a Truth and Reconciliation Commission should be established along the lines of the one in South Africa. Concerns about cultural and linguistic shift are reflected in complaints about government policy, for example the replacement of traditional chiefdoms by mayors. As well as the main elected assembly, there is a 'Customary Senate', which is consulted on matters relating to Kanak languages and cultures.

Language policy is highly relevant to the process of decolonisation and empowerment of indigenous peoples. There is an increasing number of publications on the decolonisation process and the road towards autonomy, both in French and in English: (e.g. McLellan 2005; Trépied 2011; Chappell 2013). Although several of these papers mention the language issue, very little research has focused on it.

Anthropology has a long history in New Caledonia. Studies fall into two main types. First, publications focusing on traditional customs, ceremonies and stories, especially classic studies by Maurice Leenhardt, a Protestant missionary who spent twenty years in New Caledonia during the first half of the twentieth century documenting Kanak customs and languages (Clifford 1982). This tradition continues, for example, in the journal Mwà Véé published by the Centre Culturel Tjibaou in Nouméa. Second, anthropologists are increasingly interested in decolonisation and associated processes (e.g. Naepels 2013). ${ }^{5}$ A key figure whose work links the cultural ethnographic tradition with engaged research is Alban Bensa (e.g. Bensa 2006, 2011; Bensa and Fassin 2008). Few of these researchers focus on linguistic anthropology, however. Cultural shift is, if anything, more rapid and drastic than language shift; the oral quality of Kanak tradition makes language policy central to the maintenance of tradition, which is a key concern of Kanak leaders.

\subsubsection{Language}

Although French is the only official language, under the 1998 Nouméa Accord, Kanak languages are also 'languages of education and culture'. Section 3.3 below will discuss to what extent this is reflected in policy implementation and practice.

New Caledonians of French origin (known as Canoches) are mainly monolingual in French, which is also the de facto lingua franca. None of the 
indigenous languages traditionally acted as vehicular or inter-communal language (Vernaudon 2013). In contrast to other Melanesian areas such as Papua and Vanuatu, there is no widespread creole except for Tayo, used (but dwindling) in the south. Some non-indigenous languages such as Futunan and Indonesian are now spoken by more of the population than some indigenous languages. All non-French languages are undergoing shift to some extent in Kanaky/New Caledonia, but this chapter focuses on indigenous Kanak languages, which do not have a reservoir of speakers elsewhere.

Kanak languages belong to the Oceanic sub-branch of the Austronesian language family (Moyse-Faurie, Rivierre and Vernaudon 2012), but have diverged considerably from their common Proto-Oceanic ancestor. They are seen by historical linguists as 'badly behaved' or 'aberrant' Melanesian languages (Grace 1981; Pawley 2006), as they exhibit a high degree of differentiation and complexification in all domains: phonology (Rivierre 1994), lexis (Rivierre 1994; Bril 2000), morpho-syntax (Pawley 2006). They can also vary widely within a community of speakers, for both language-internal and language-external reasons, and there is a long tradition of pluri-/multilingualism and language contact. According to the Kanak Languages Academy (hereafter, ALK - see Section 3.3) there are twenty-eight extant indigenous Kanak languages. However, there are discrepancies and inconsistencies in the numbers, names and spellings of indigenous languages listed by sources such as Ethnologue and the ALK, and even between the ALK list and the text and map on its web page. ${ }^{6}$ Ethnologue lists thirty-one living Kanak languages plus two which are no longer spoken, the creole Tayo, and five immigrant languages including French. ${ }^{7}$ The Kanak languages with the largest numbers of speakers, and which have the highest ethnolinguistic vitality, are spoken by people from the Loyalty Islands to the east of Grande Terre. These islands were Christianised by Protestant missionaries who translated the Bible into indigenous languages, which contributed to their maintenance. Grande Terre is predominantly Catholic; Catholic churches and schools use French.

Over half of the population lives in or around the capital, Nouméa, which is the only major conurbation. Although the majority of the inhabitants of Nouméa are non-indigenous, an increasing number of Kanak people are moving to the capital, if only temporarily for education purposes (there are no post-secondary education institutions outside Nouméa). Language maps of Kanaky/New Caledonia generally show languages in the 'Customary areas' that they originate from (see Figure 3.1). The structure of the ALK follows these areas, which does not take into account increasing urbanisation, although the ALK is aware of the 'problem' of urban plurilingualism. According to le Centre de Documentation Pédagogique de la Nouvelle-Calédonie (CDP-NC), ${ }^{8}$ 40 per cent of the inhabitants of greater Nouméa speak a Kanak language (mainly from the Loyalty Islands), but rapid language shift is in progress there, 
as a monolingual ideology predominates. Part of the role of this government agency is to promote the cognitive and social benefits of bi/multilingualism, especially in the family. There is still a marked difference between the way of life and language practices in rural areas and in the capital, although conveniences such as satellite television and an exponential increase in car use contribute to increasing challenges to traditional customs.

Most speakers of other languages are bilingual in French - according to CDP-NC and Salaün (2007) 97 per cent of the population can speak or write French. There is little cross-community language sharing and French is seen as the 'natural' lingua franca between different language communities in both urban and rural areas, replacing the traditional model of dialect continua, multilingualism and mutual comprehensibility between neighbouring Kanak languages. Endogamy is common between small groups such as speakers of Caac and its neighbouring languages Jawe and Nyelâyu; traditionally women would learn the languages of their husbands, but nowadays couples from different language groups tend to speak French with each other and their children.

Kanak languages were banned from the education system from 1863 until 1984 (Vernaudon 2011). It was not until the political emancipation movement in the late twentieth century that they eventually (gradually) attained institutional recognition. Salaün $(2005,2010)$ argues that while the exclusion of 'indigenous idioms' from education was often reiterated, French was superimposed on local languages 'rather than contributing to their disappearance'. However, language shift has intensified since 1945 (Vernaudon 2013). Of the thirty-eight total living languages in New Caledonia listed by Ethnologue, 'twenty-four are in trouble, and seven are dying'. ${ }^{9}$ Ethnologue categorises three of the thirty-two living indigenous languages (including Tayo) as 'nearly extinct' (e.g. Arhö had only ten speakers in 2000), three more as 'moribund' (no longer learnt by children in the home), eight as 'shifting', and ten as 'threatened' (including Caac, discussed in Section 3.2). Non-indigenous languages such as East Futunan and Bislama are also listed as threatened in New Caledonia. As part of the implementation of the Nouméa Accord of 1998, the ALK was founded in 2007: its remit is to promote Kanak languages as 'languages of culture and of education', focusing on corpus planning, standardisation and orthography development. Its role will be discussed further in Section 3.3 below.

Despite its relative proximity to Australia, a large English-speaking nation, the media in New Caledonia are overwhelmingly oriented towards other francophone areas, especially metropolitan France and other francophone territories in Oceania. Print and broadcast media seem to be largely produced by and for people of European origin; Kanak people, languages and culture are largely invisible. While I was staying in Pweevo, a drama-documentary was shown on television about Louise Michel, a political activist who was 
deported to New Caledonia after the Paris Commune uprising in $1871^{10}$ and who befriended Kanaks and supported them in their anti-colonial struggle. My host family showed great interest in this and it was made clear that it was one of the few programmes to feature Kanak people at all. ${ }^{11}$ I was told that there are plans for a Kanak television channel - in French but showing programmes on Kanak cultural topics. There has been a Kanak radio station, Radio Djiido, since 1985 but, likewise, little of its output is in Kanak languages. Since the Matignon Accord there has been a resurgence in Kanak cultural expression, encouraged by government agencies such as the Agency for the Development of Kanak Culture (Hayward 1998: 52), which sponsors musical events.

Linguistic research in Kanaky/New Caledonia has focused mainly on language documentation and description: partly under the auspices of the ALK and partly by researchers connected with INALCO ${ }^{12}$ and LACITO $^{13}$ in Paris, often in collaboration with the University of New Caledonia. As noted in the Introduction, little sociolinguistic research has been carried out, especially into language attitudes and ideologies related to language shift, language change and language policy. The next sections describe a small-scale initial attempt at such research.

\subsection{Attitudes towards language in Pouébo/Pweevo}

Pweevo $^{14}$ is a small town in the Hoot Ma Waap customary area, Northern Province, which is the most linguistically diverse area of New Caledonia. The main language is Caac, which in the 2009 census had approximately 890 speakers aged 14 years or over (Leclerc 2014). Despite its small size, Pweevo acts as an educational centre for the surrounding area, and children attend schools there from two adjacent language areas, Jawe and Nyelâyu, with which there is a degree of mutual comprehensibility due to contact influence and familiarity. However, as stated above, if children want to continue their education beyond age 16 they need to move to Nouméa, a seven-hour bus journey from Pweevo. Pweevo is a rural town, with homesteads dispersed among lush vegetation. Nearly all the inhabitants are related in some way, and I was told that there is no word for 'unrelated friend' in Caac; kinship terms express all relationships. As well as primary and secondary schools (both Catholic and secular), the town has a market building, a church, a community centre, a médiatheque (multimedia library), and a couple of grocery shops. Family homes consist of clusters of buildings, at least one of which is often in traditional Kanak style, often round, with a thatched roof. Traditionalists include carved door posts and rooftop finials, both of which are iconic of Kanak identity. All the homes I visited had electricity, running water (not necessarily hot) and satellite television. Mobile phones are ubiquitous as there are few land phone lines, although the signal was only strong enough for texting. Internet access is only available in 
the médiatheque and schools. Television brings Western culture and language; Disney Channel (in French) is popular with children. Older respondents see language loss and change as symptomatic of the loss of culture and traditions.

I carried out a small-scale sociolinguistic study of language attitudes and practices in Pweevo in March 2013. Largely unstructured interviews were conducted with twenty-five community members, including a local politician, a former mayor and the Hoot Ma Waap delegate of the ALK, women at the market and members of my host family, members of a church youth group (group discussion and short individual interviews), and two Caac-speaking students in Nouméa, as well as with Aurélie Cauchard, a linguist documenting Caac who introduced me to many of these contacts, and another linguist who is a member of the ALK's Scientific Advisory Committee. Interviews were carried out in French: some were recorded, whereas I took notes in English during others, depending on the preference of the interviewees, practicalities and acoustics (it was not practicable, for example, to record conversations at the market hall). Some comments from interviewees are therefore paraphrased in this chapter.

Several interviewees, especially middle-aged men, expressed concern about the way the Caac language is spoken nowadays and at the loss of traditional culture. In an oral tradition where the words pronounced on formal occasions form the base of social interactions and organisation, rapid transformation of the language, along with the cultural shift towards a more Westernised way of life, trigger strong sentiments in favour of the preservation of linguistic and cultural identity. Most interviews were preceded by the 'customary gesture', a short formal speech asking for permission to enter the home, which involves gifts, generally a token small sum of money and a length of cloth. The gesture carries obligations for both sides: I was promising to respect tradition as well as research ethics, and by accepting the gifts, interviewees were effectively undertaking to participate in future. However, when I visited the Catholic primary school to interview teachers, who were all young women, and tried to initiate the customary gesture, I was told gardez ça pour les vieux ('keep that for the old people/elders'). ${ }^{15}$

Language and culture are seen as intertwined but not necessarily inseparable: 'The language is disappearing - and culture with it.' People are realising how little they know of traditions, for instance, it is becoming difficult to find people who can retell old stories. Children are déraciné (uprooted) and 'young people don't see traditional culture as relevant to them'. Language is seen as 'almost the last thing we have left' of the traditional way of life, since to an extent it can survive cultural shift. Nevertheless, people who express such sentiments do not always speak local languages with their children.

Caac speakers express regret at the way they 'shorten words', the fact that they borrow many words from French, that they do not remember some Caac terms (e.g. the numerical system) or that it is becoming common to 'start a 
sentence in Caac and finish it in French'. They categorise certain variants as belonging to 'old/true Caac' and interpret 'Present-Day Caac' as indicating attrition. ${ }^{16}$

Some of the comments reveal ongoing internalised ideologies of inferiority and negative attitudes towards Kanak languages. Some parents acknowledged that they speak French to their children 'to help them get on in school and life'. The idea that 'French is the language of success' is transmitted to young people: this particular quote is from a university student studying Oceanic languages. In some domains French is seen as the natural choice, for example days of week or financial accounting, which were not part of the traditional way of life. When I visited the market in Pweevo, the stallholders (all women) were coming to the end of a meeting. The majority of the proceedings took place in Caac, but the financial statement was read out in French. I remarked on this to some of the participants, some of whom replied that 'she ought to try to say that in Caac', while others observed that 'there are words we don't have in the language'. At the same time, there is recognition of the uniqueness of Caac: language is rooted in clan, land and location, which is at the heart of Kanak culture. This leads to a rhetoric that 'our language is only spoken here, therefore it's important to save it'. Resistance to colonial influence is reflected in statements such as 'We should ban French', although this is unrealistic given the ubiquity of French as a language of wider communication both in New Caledonia and beyond.

Several informants expressed resignation in the face of language and cultural shift: 'It's too late to save our language'; 'We can only save the language and culture by turning back time' (cf. Salaün 2005). Nevertheless, there are organised language maintenance activities. A local language committee is 'working on the language' with Aurélie Cauchard; I was told that it had been prompted by the linguist's arrival to reconvene after five years of inactivity. I was curious to find out what 'working on the language' meant, and was told that the committee is collecting words for a dictionary of Caac: starting with the human body, then moving to what humans need to eat, how food is grown, etc., places, and genealogies, which is seen as an appropriate approach culturally. There are also 'animations' (guided activities) at an after-school club held at the community centre. Topics include local history, customs and nature as well as language, which is the focus once a month. Language activities have included an Easter egg hunt with clues in Caac (with the added incentive of chocolate). These efforts to motivate children to take an interest in heritage and culture, however, need to be seen in comparison to the power of the monolithic French education system. Local culture and associated areas are not part of the mainstream curriculum, so the fact that the activities are extra-curricular, short and fun may send a subliminal message to children about what is important to include in serious education and what is not. What is more, language is only 
the focus for about half an hour a month, which the animatrices recognised was not enough to consolidate language skills in children whose French was stronger than their Caac. As with other 'community' initiatives such as farming and fishing co-operatives, the after-school clubs are state funded: activities are planned in a 'top-down' manner by 'the president of the association' rather than by the local animatrices. Despite, or because of, the history of political activism and resistance, 'bottom-up' empowerment does not seem to be encouraged. Despite such attitudes, informants also showed awareness of the need for grass-roots involvement in language maintenance: 'It's the responsibility of parents to speak'; and 'Teaching the languages will help, and children's books, but people have to want it too.' A community worker commented that 'Parents need to be more aware of language situation, and the benefits of bilingualism.' As discussed in Section 3.3 below, the CDP-NC promotes bilingualism through children's publications, but these need to be reinforced both inside and outside the classroom by, for example, positive images in the media.

\subsubsection{Young people's language practices}

Most interviewees (parents, teachers and young people) reported that children now prefer to speak French rather than Caac: 'Children reply in French'; 'The younger the child, the more likely to speak French'; '[Children] don't understand all the Caac words'; and '[Many children] can't speak their mother tongue'. Some parents claimed that even if they try to transmit Caac, children learn French from their playmates (I too observed children interacting with each other in French). One mother stated that when she spoke to her children in Caac they answered in French, yet they spoke to each other in Caac. Reflecting on why, she suggested that it might be due to the children's lack of confidence in their ability to speak Caac adequately, which might be a reaction to adult attitudes towards children's language practices, as discussed below. Teachers at the Catholic infant school in Pweevo reported that of twenty-one children in the reception class (which children attend from two years, nine months), only one spoke fluent ('good') Caac. Although the school catchment area includes families from neighbouring language areas, nearly all the children in this class came from Caac backgrounds. One infant teacher reported asking a child to say 'mama' in Caac, but the child didn't know how. These reports were confirmed at the ALK regarding other regions (see below).

The research revealed widespread stigmatisation of the language practices of young people, which might discourage the maintenance of indigenous languages. Younger informants acknowledged that, for them, French comes more easily and is not necessarily a conscious choice. Parents and grandparents complain that children speak 'deformed Caac' and criticise them; children respond with reluctance to speak it. This raises the issue of what parents 
and teachers mean by 'good Caac'. It was reported by both local people and Aurélie Cauchard that young speakers of Caac use different words from their elders, sometimes influenced by French, which led middle-aged informants to claim that 'authentic Caac' is being lost. Younger speakers use abbreviations and 'can't pronounce it properly'. Such opinions are not uncommon reactions to language change around the world, and indicate a lack of recognition or acceptance of the fact of language change over generations. In this respect, it is worth recalling that Kanak languages have always borrowed both lexis and phonology, as noted in Section 3.1.2 above, but convergence with French is seen as undesirable.

The young adults I interviewed were aware of code-switching: 'We often put French words into Caac - we don't know why'; and 'We rarely finish a conversation all in Caac'. They accepted code-switching as an effective way of utilising all their linguistic resources but were also aware that older people see it as undesirable and as indicating deterioration of both proficiency and purity in Caac. Young people were also perceived as using less respectful language than their elders, part of concern for the loss of cultural traditions. A university student observed that 'An old lady told me my way of speaking disturbed her ... there's a gulf between our generation and our grandparents [...] we have to preserve the language by adapting it'. It was claimed that teenagers don't consider Caac to be cool, but that some start speaking it again to return to their roots after leaving school. However, this may not be the case if they move to the capital for further/higher education or to seek employment.

\subsection{Language policy and ideologies}

As mentioned above, the Kanak Languages Academy was founded in 2007 under the 1998 Nouméa Accord, which recognised Kanak languages as langues d'enseignement et de culture (languages of education and culture). The ALK's main aims are 'to fix the rules of usage and to contribute to promoting and developing Kanak languages and dialects as a whole' ${ }^{17}$ It is seen generally as a positive development which 'will raise the status of our languages', according to one of the university students interviewed. I attended a meeting of the ALK in March 2013 whose purpose was to take stock of achievements in its first five years of existence. Speakers noted that language documentation was progressing well, and that the Academy was moving 'from codification to normalisation'. The ALK sees the main barrier to the promotion of Kanak languages as their lack of written standardisation. It thus appears to replicate a Western/French language ideology which places primary importance on written standards rather than everyday spoken language practices, and which is fixated on norms. Despite the cultural importance of orality mentioned in Section 3.2 above, the ALK sees its main mission as: '[D]etermining 
a normalised alphabetic code for each language in a region ... [followed by] dissemination to as many people as possible via literacy training in order to promote its use' (my translation)..$^{18}$ There is no mention of addressing language shift. Language contact and change are not mentioned per se, although it can be deduced that 'fixing the rules' implies 'negatively sanctioning variability' (Woolard 1998: 17).

Much of the discussion at the March 2013 ALK meeting revolved around spelling. The ALK publishes 'propositions' for orthographies for selected Kanak languages. ${ }^{19}$ These follow an 'autonomous' or technocratic view of literacy, taking for granted the optimality of phoneme-grapheme correspondence (Street 1984; Grenoble and Whaley 2006). But, as we have seen in Pweevo, pronunciation varies according to regional accent, age, family and clan idiolects, etc. The ALK-sponsored orthographies tend to be seen as authoritative (or prescriptive), although representatives of the ALK were at pains to stress that they were 'just proposals'. Among some delegates there was strong (literally religious) attachment to spellings introduced by Protestant missionaries for certain languages. Certain spellings and diacritics have come to be seen as iconic (Sebba 2007): 'How can we pronounce words correctly without the trema?' lamented one delegate. But the primacy of writing was not challenged; despite the theme of the conference being 'Espace oralité, the focus was exclusively on writing and formal education. Writing was even described by a delegate as having the ability to 'rectify the oral', which 'can deform' usage. According to a linguist from the scientific committee of the ALK, 'The principle of one phoneme equals one grapheme makes it easier to learn to read.' However, orthographic depth is of varying usefulness depending on whether readers are first- or second-language speakers, latent speakers, or rememberers, which raises the question of who the orthographies, and the materials produced, are for. I found evidence in Pweevo that ordinary people find 'linguists' spellings' difficult to process, since they tend to follow English sound-spelling conventions such as $<j>$ for $/ \mathrm{d} z /$ and $<w>$ for $/ w /$. This can also be seen as a distanciation strategy: the letter $\langle\mathrm{k}\rangle$ is seen as iconic by Kanak activists in opposition to the older spelling canaque, now seen as racist. Yet most people are literate through French only, which has no /dz/ sound and uses <ou $>$ for /w/. The majority of writing in Caac by speakers is in mobile phone texts. Users reported that they spell 'in the way it sounds to me', that is, using French spelling conventions.

The ongoing language shift described in Section 3.1.2 is usually blamed on schools or the Catholic church (which also runs schools): I was told by several people that 'the nuns [bonnes soeurs] used to hit our fingers with a ruler if we spoke our language'. However, since 2005, it has been official policy for schools to encourage parents to speak home languages rather than French with children. Home languages are tolerated in schools (at least in the early years), 
with language support assistants provided to explain concepts in home languages since not all teachers speak them. This policy change is not, however, intended to support home language maintenance, but is a transitional model to improve the children's ultimate acquisition of French. The Pweevo teachers stated that children's language development was suffering from the poor French of their parents, so it was surmised that children would learn 'better' (i.e. standard) French at school if they used their heritage languages at home rather than accented French or a local dialect of French with contact influences from Kanak languages. Nevertheless, many of the parents I spoke to were unaware of this change in policy and assumed that local languages were still banned from schools; the teachers also reported that children informed them that they were not allowed to speak Caac at school.

From 2002-4 and since 2005 there have been experimental projects in place to teach 'Langues et Culture Kanak' (Kanak languages and culture) in selected primary schools. Nocus et al. (2010) present an interim report on a psycholinguistic and sociolinguistic evaluation of two project schools in Northern Province and the Loyalty Islands. ${ }^{20}$ The study found evidence of beneficial effects of teaching Kanak languages, and no deleterious ones, in terms of children's language development in French, their literacy development in both French and the local Kanak language, other subjects, and heritage language maintenance in the family. The authors point out that although parents' responses to the programme have been overwhelmingly positive, the government hesitates to extend it beyond primary school level. The programme is described as 'bilingual', but exactly what is taught, and how, is not described by Nocus et al. (2010). From discussions at the ALK meeting in March 2013, it would seem that these lessons actually teach linguistic and cultural awareness as a subject rather than implementing bilingual education. There appear to be no plans to introduce wider literacy through local languages. Salaün (2007) reports that the possibility that Kanak languages might be used as a medium of education is not even considered. The goal of the 'Kanak languages and culture' lessons seems to be valorisation, a necessary step in the promotion of additive bilingualism (as highlighted by the CDP-NC). In terms of models of bilingual education, it is not even transitional, let alone a language maintenance programme. Salaün (2007: 267) reports that "the "denial of the didactic function of Kanak languages" (see Fillol and Vernaudon, 2004) subsists to this day', and that the programmes introduced in 2005 were not supported by Kanak parties because they were 'too conditional'.

It could be argued that Langues et Culture Kanak-type awareness classes are suited to a highly diverse linguistic environment such as prevails in greater Nouméa. On the other hand, like the ALK's corpus planning, they assume that 'home' languages are actually being transmitted and maintained in the home. The reports by teachers in Pweevo that many children cannot speak 
their 'home' languages were confirmed as typical by ALK delegates; in Nocus et al. (2010) 70 per cent of the children self-identified as French-dominant. As pointed out by May and Hill (2008) and Hinton (2011), it is often assumed in bilingual/immersion programmes that the target minority language is the home or first language of the children, but this is not necessarily the case and can, of course, make a huge difference to teaching methodology and outcomes. Nocus et al. (2010) do not discuss the availability of educational materials in Kanak languages or teacher training in bilingual education. While the ALK's main focus is corpus planning, it also produces videos and children's story books in Kanak languages, as well as leaflets with ideas for language games. The CDP-NC too produces educational materials in both indigenous and non-indigenous languages; its website includes electronic versions with audio. What is unclear is how these materials, which are mainly story books for children, relate to or integrate into the curriculum (either mainstream or Langues et Culture Kanak). It became clear from talking to linguists working for the ALK that they had little or no training in applied or educational linguistics or in sociolinguistics.

\subsection{Conclusions}

In an extract from an interview in 1985 which is frequently cited in current nation-building discourse in New Caledonia, Jean-Marie Tjibaou (a leader of the Kanak independence movement until his assassination in 1989), stated that what is thought of as tradition is actually in a constant state of evolution: 'The return to tradition is a myth. No people has ever experienced it. Insofar as I am concerned, the search for identity, the model, lies before us, never behind. It is being constantly reformulated' (Tjibaou 1985: 1601; translation from Waddell 2008: 102). This quotation is just as relevant to the revitalisation of heritage languages as to cultural traditions. Despite the nostalgia associated with many cultural and linguistic revival movements, it is not possible to return to pre-colonial language uses or usage.

Recognition of Kanak languages as 'languages of education and culture' may have contributed to Kanak empowerment, but indigenous languages still have a very limited place in public life, including the education system (see also, for example, Sherris and Robbins, this volume). Language policy making tends to be 'top-down', even at community level. As noted above, there has been very little sociolinguistic research in Kanaky/New Caledonia (as distinct from pedagogical research, language description or anthropology). Linguists developing materials have little knowledge of social factors in language and literacy, applied linguistics or educational development. There is therefore a need for both wider training and collaboration, as well as larger-scale sociolinguistic research which is responsive to community concerns. Promotion of low-status 
languages cannot be effective without understanding and addressing attitudes and ideologies (see also Valdovinos, this volume).

\section{NOTES}

1 Naming Kanaky/New Caledonia is a matter of huge debate. In August 2013, France's Overseas Minister Victorin Lurel 'dared' to say the name Kanaky, which caused uproar in the territory, somewhat to Lurel's bemusement: he commented 'Yes, I said Kanaky, but is it a swear word?' (Tingal 2013). Some have suggested a compromise combining the two names, along the lines of Papua New Guinea (Sylvain Pabouty, quoted in Chappel 2013). However, the order of the names is also disputed.

2 www.world-of-islands.com/Infos/Civilisation/Langues_NC_fr.htm (last accessed 20 February 2015).

32009 census, www.insee.fr/fr/themes/document.asp?ref_id=ip1338 (last accessed 20 February 2015).

4 According to the Pacific Institute of Public Policy, 'There are still some remaining powers to be transferred under Article 27 of a 1999 organic law (including tertiary education; audio-visual communication; and control of accounting and financial reporting for the Provinces, local councils and other public institutions). This step must be concluded before a date can be set for a referendum on self-determination.' (http://pacificpolicy.org/2014/08/new-caledonias-elections-and-the-qu est-for-independence/, accessed 20 March 2015).

5 Le Groupe de recherchésur les enjeux sociaux comtemporains en Nouvelle-Calédonie [Research group on contemporary social issues in New Caledonia] provides a cross-disciplinary site for disseminating research in related fields. See www .recherches-nouvelle-caledonie.org/ (last accessed 20 February 2015).

6 Although the ALK text states that twenty-eight Kanak languages are still spoken, it lists thirty-two, while its map shows thirty-four. www.alk.gouv.nc/portal/page/portal/alk/langues/presentation (last accessed 20 February 2015).

7 www.ethnologue.com/country/NC/status (last accessed 20 February 2015). According to the website Corpus de la Parole, the lack of clarity is because it is not easy to distinguish between languages and dialects: http://corpusdelaparole .huma-num.fr/spip.php?article24 (last accessed 20 March 2015).

8 New Caledonia Centre for Educational Documentation, www.cdp.nc/index.php/ le-cdp-nc/ (last accessed 20 February 2015).

9 www.ethnologue.com/country/NC/ (last accessed 20 February 2015).

10 New Caledonia was used as a penal colony from 1863 to 1897 . The main internees were petty criminals, but they included some political prisoners from the Paris Commune, as well as Kabyle rebels deported from Algeria in the 1870s. Michel published a book on Kanak customs and mythology (Michel 1885).

11 Many programmes are imported and dubbed into French. Virtually the only other non-white people featured on television are in American dramas or Moroccan soap operas.

12 www.inalco.fr (last accessed 20 February 2015).

13 http://lacito.vjf.cnrs.fr/ (last accessed 20 February 2015). 
14 Pouébo is the more widely known French spelling, while Pweevo is the ALK-sponsored Caac spelling. This chapter uses the latter to valorise local language.

15 Aurélie Cauchard comments that they could well have meant that I should give this to someone who could receive it, like an elder (personal communication, 6 October 2014).

16 Aurélie Cauchard has collected linguistic data on language change in Caac.

17 « fixer les règles d'usage et de concourir à la promotion et au développement de l'ensemble des langues et dialectes kanak » www.alk.gouv.nc/portal/page/portal/ alk/ (last accessed 20 February 2015; my translation).

18 www.alk.gouv.nc/portal/page/portal/alk/alk/missions (last accessed 20 February 2015).

19 The orthographies are published on the ALK website, including sound files of example words, e.g. www.alk.gouv.nc/portal/page/portal/alk/langues/cemuhi/correspondances_cemuhi (last accessed 20 February 2015).

20 The research is part of a wider ongoing study comparing outcomes in other French overseas territories, namely Tahiti and Guyana: www.ecolpom.univ-nantes.fr/ (last accessed 20 February 2015). 